\title{
NOTE ON LEPEOPHTHEIRUS SEMICOSSYPHI YAMAGUTI (COPEPODA : CALIGOIDA)
}

AUTHOR(S):

Shiino, Sueo M.

\section{CITATION:}

Shiino, SUeo M.. NOTE ON LEPEOPHTHEIRUS SEMICOSSYPHI YAMAGUTI (COPEPODA: CALIGOIDA). PUBLICATIONS OF THE SETO MARINE BIOLOGICAL LABORATORY 1963, 11(2): 409-414

ISSUE DATE:

1963-12-31

URL:

http://hdl.handle.net/2433/175333

RIGHT: 


\title{
NOTE ON LEPEOPHTHEIRUS SEMICOSSYPHI YAMAGUTI (COPEPODA : CALIGOIDA)
}

\author{
Sueo M. SHIINO \\ Zoological Institute, Faculty of Fisheries, \\ Prefectural University of Mie
}

With 2 Text-figures

In erecting Lepeophtheirus semicossyphi YAMAGUTI the original author (1939) gave the definition of the species on the basis of the adult and juvenile females obtained from the gills of Semicossyphus reticulatus Valenciennes. Although he mistook the juvenile females for the males at that time, he and Yamasu (1959) discovered the true males later and issued a detailed description of this sex, making in addition some rectifications to the previous diagnosis of the female.

Recently, through the courtesy of Dr. T. Tokioka of Seto Marine Biological Laboratory, I had an opportunity to study a number of specimens of this species taken from the fishes kept in the water-tank of Shimonoseki Aquarium. On closer examination of both the sexes it proved that the original descriptions and figures leave something to be desired, especially with respect to the characters of the female. A brief account based on the present specimens will be given here as a supplement.

According to the description on the label attached to the vial, the specimens were found at least on three species of fishes inclusive of the type host. This may probably be due to the accidental migration of the parasites from the legitimate host to other kinds of fishes which were kept in one and the same aquarium.

It is my pleasure to record here a dept of gratitude to Dr. T. TokiokA for his kindness in providing me with the material.

\section{Lepeophtheirus semicossyphi YAMAGUTI}

(Figs. 1 and 2)

YAMAGUTI 1939: 449-451, Pl. XV, Figs. 14-21, P1. XVI, Figs. 22-24.

Yamaguti and Yamasu 1959: 120-121, Pl. VIII, Figs. 165-177.

Publ. Seto Mar. Biol. Lab., XI (2), 1963. (Article 25) 
410

A

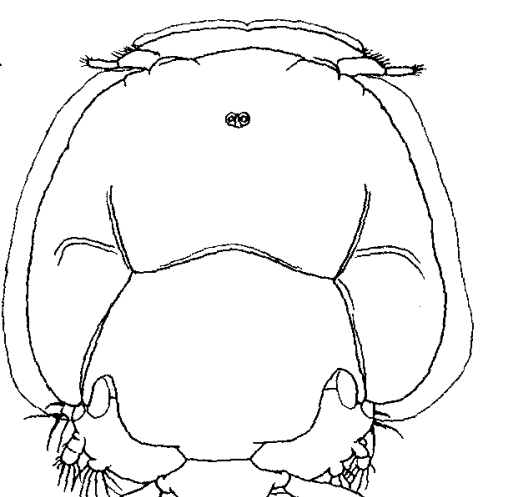

S. M. SHIINo

B
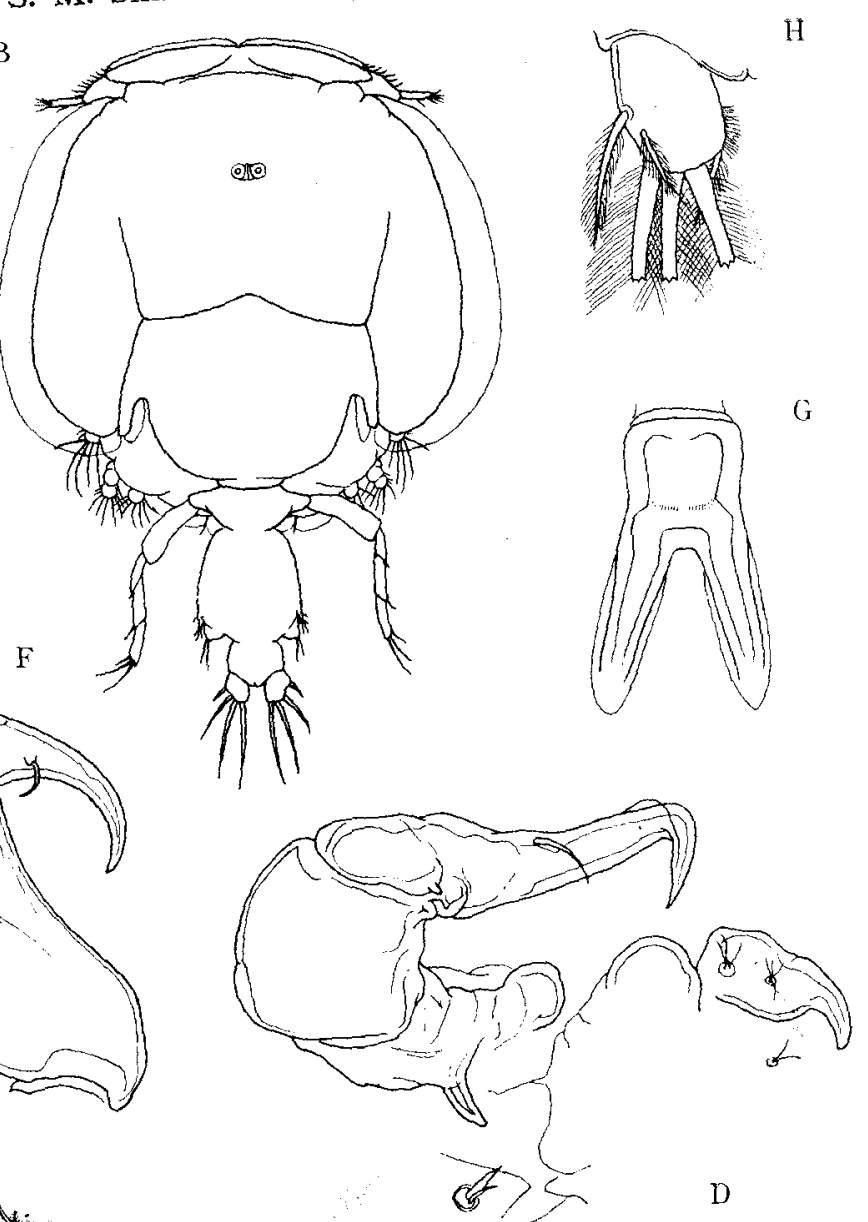

C
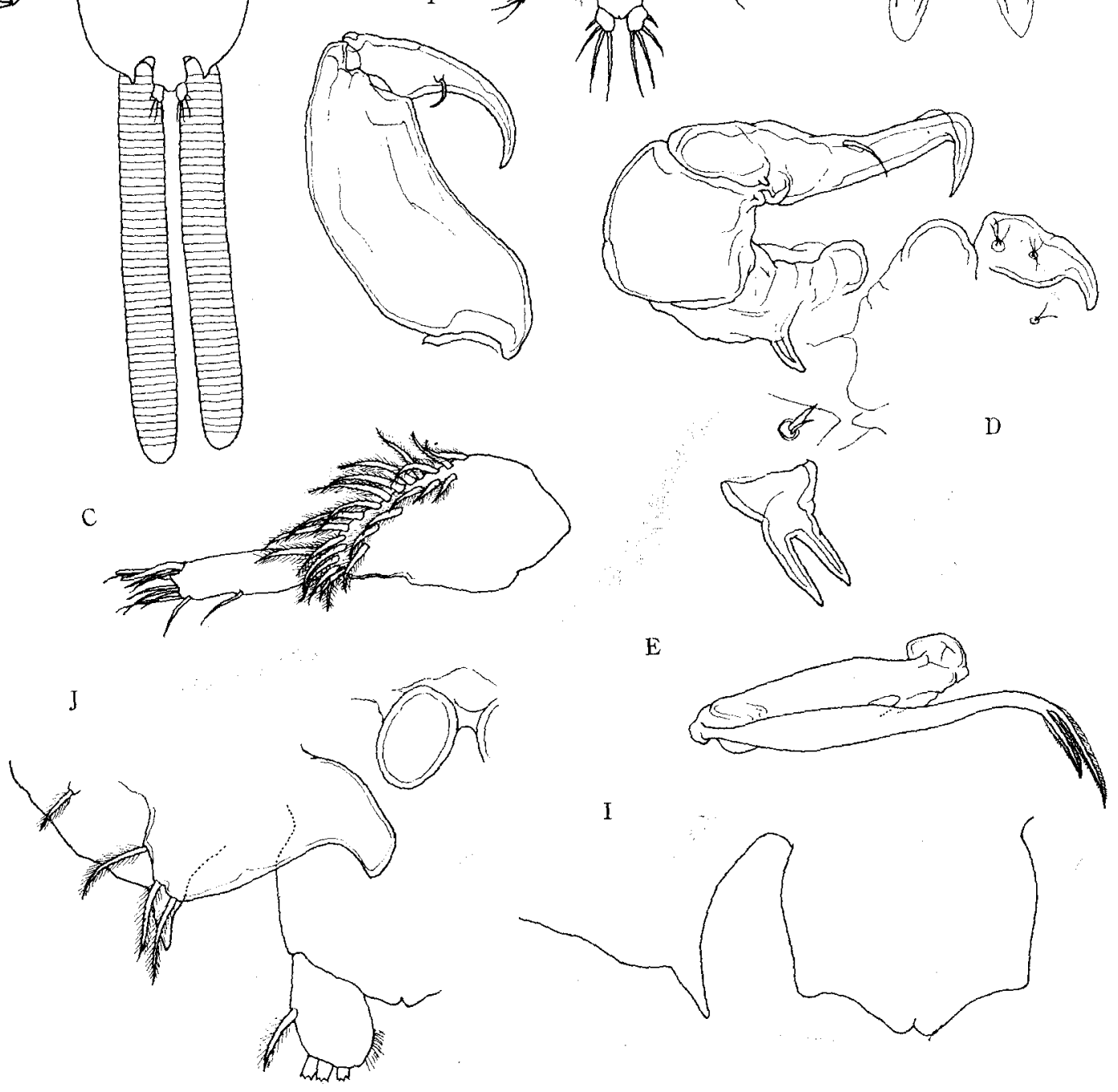
Occurrence: 5 females and 4 males found parasitic on the outer surface of Semicossyphus reticulatus VALENCIENNES, Chaerodon azurio (JORDAN and SNYDER), Spheroides pardalis (TEMminck and SCHLEGEL) etc. kept in Shimonoseki City Aquarium in 1963. Both sexes whitish in alcohol, with central area of carapace and genital segment showing a dirty yellowish tone.

Female: The largest female $5.53 \mathrm{~mm} \times 3.31 \mathrm{~mm}$, with egg tube of $3.55 \mathrm{~mm}$ long, and the smallest female $4.77 \mathrm{~mm} \times 3.00 \mathrm{~mm}$, with egg tube of $1.69 \mathrm{~mm}$ long. The line of border between the fourth and the genital segments is indistinct. The latter segment has well round sides, showing a circular outline and is produced into a narrow triangular lobe on the caudal margin on either side of the abdomen, from which the lobe is separated by a deep notch. The lobe is very thin, transparent and lies just above the attachment of the egg tube unlike that represented in YamaGu tr's figure (1939, Pl. XV, Fig. 14), in which the genital segment carries the egg tubes on its dorsal surface.

The second antenna has a narrow chitinous rim near the tip of the hooklike distal joint and a short papilliform hair rudiment at the base besides the well-developed hair located more distally. Basal joint is armed with a stout unguiform process on the posterior side. The claw of the first maxilla is short, and the second maxilla is bifurcate. The first maxilliped bears a membraneous lamina at about the middle of the distal joint which ends in two unequal claws with narrow pectinate rims. The second maxilliped has the palm well swollen, convex on the outside, but concave on the inside; the terminal claw is powerful, well curved, and carries a short sub-basal hair. These appendages are illustrated here for the first time.

Of four terminal spines on the first leg, the external three are simple, feebly pectinate and associated at their bases each with a small pectinate lamina; the innermost spine has double row of short hairs. The protopodite of the second leg and the first exopodite joint of the same leg are fringed by a broad membraneous flange on their external border. The outer spine on the latter joint bears a narrow rim on the sides and a small basal pectinate lamina. The corresponding spine on the second joint is similarly rimmed, but lacking in the basal lamina. The proximalmost of three external spines on the third joint is simple, the middle member is recurved and rimmed by broader outer and narrower inner chitinous membranes, and the distalmost is much longer and fringed by broader external membrane and internal row of hairs. The terminal spines on the distal two joints of the fourth leg are doubly edged by

Fig. 1. Lepeophtheirus semicossyphi YamaGutI. A, female, dorsal view ; B, male, dorsal view ; C-J, female ; C, 1st antenna, ventral view; $D$, 2nd antenna, 1st and 2nd maxillae in situ ; E, 1st maxilliped ; F, 2nd maxilliped ; G, sternal furca ; H, caudal ramus ; I, abdomen and caudo-lateral angle of genital segment, showing 5 th and 6 th leg rudiments, ventral view. A $\times 14, \mathrm{~B} \times 21, \mathrm{C}, \mathrm{D}, \mathrm{G}-\mathrm{J} \times 82, \mathrm{E}, \mathrm{F} \times 52$. 


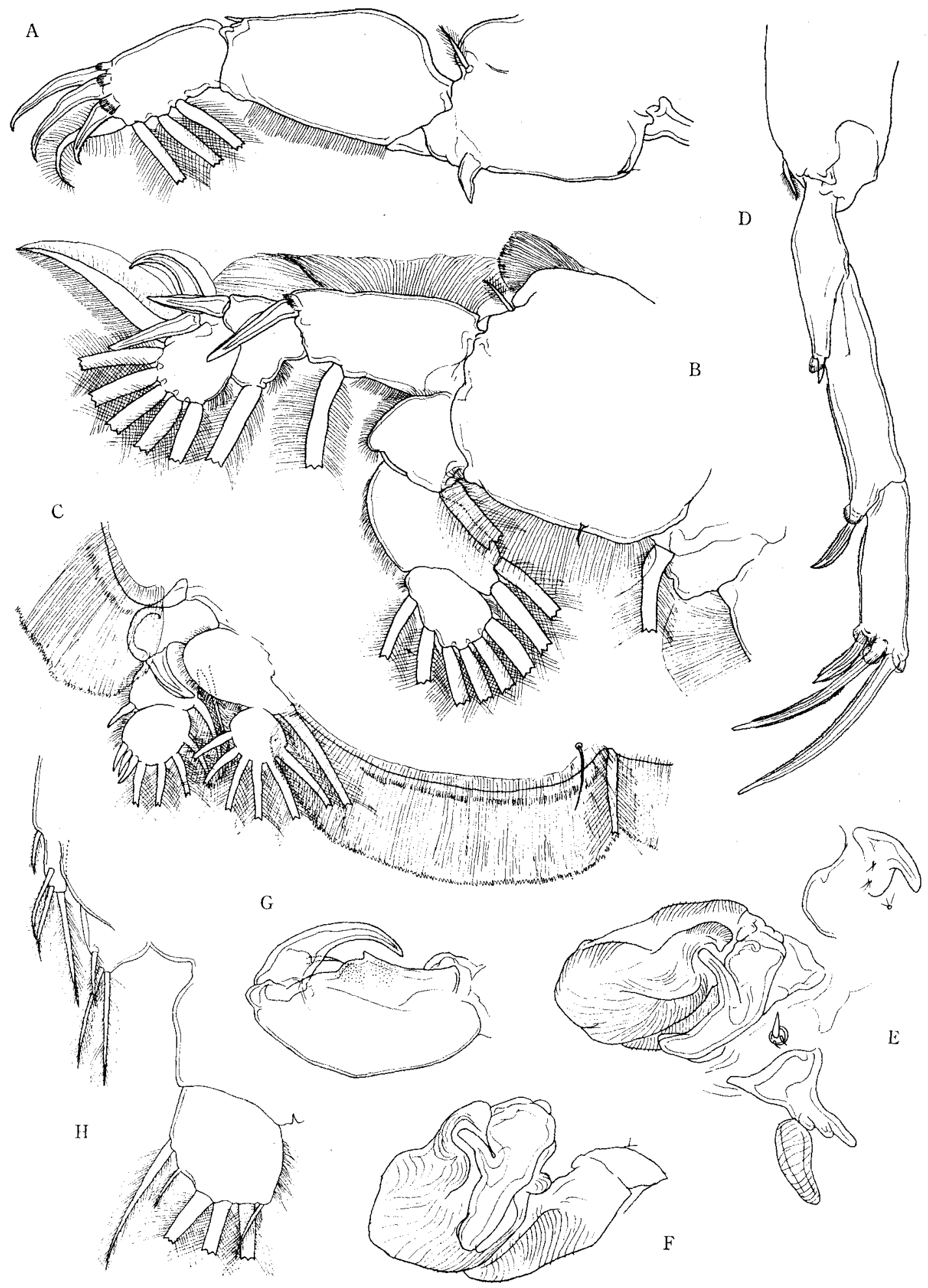


narrow pectinate rims and accompanied each with a similarly pectinate basal lamina. The spine of the second joint is much reduced though with the basal lamina. The sixth leg is represented by a transverse broad plate situated on the ventral side of the genital segment just internally to its caudo-lateral angle. The leg carries three short plumose hairs on the outer margin and is produced inward beneath the abdomen into a narrow free lobe which is turned caudad thus giving to its posterior margin an excavated appearance. The attachment of each egg tube is interposed between this leg and the triangular caudal process of the segment. The sixth leg was erroneously illustrated by the original author as if it were a hemi-oval lobe distinct from the inner portion of the leg (1939, Pl. XV, Fig. 17). In reality, however, the inner projection of the segment in his figure is continuous with the setiferous leg and nothing but its inner free lamina.

Male: The largest male measures $3.24 \mathrm{~mm} \times 1.77 \mathrm{~mm}$, and the smallest one $2.93 \mathrm{~mm} \times 1.92 \mathrm{~mm}$. Not to mention the configuration of the genital segment, conspicuous sexual dimorphisms are found in the structure of the second antenna, the first and second maxillae and the second maxilliped. The apical joint of the second antenna is bifid, never simple as figured by YAMAGUTI and YAMASU; the main stem of the joint is doubly edged with narrow chitinous rim and the accessory branch, which is slenderer and yet relatively stout, is turned antero-proximally. The second joint is raised on its ventral surface into a broad longitudinal ridge, which is excavated at the end to receive the tip of the accessory branch of the third joint and has a small bulge on the posterior side near the end. The first and second joints show rugosity on their surface owing to the development of wavy, more or less parallel stripes of chitinous surface. The first maxilla has a triangular base and a claw not much stouter than in the female. The second maxilla bears two short accessory branches arranged proximo-distally on the inner border. The second maxilliped is not particularly powerful unlike in other caligoids where this is usually much stouter in the male. It bears on the inner margin of the palm a low bulge which is surmounted by a short but sharp process and finely granulated on the surface. The fifth and sixth leg rudiments are exactly as those described and figured by YAMAGUTI and Yamasu. The abdomen is relatively a little wider than in the female and has broader caudal rami ending in stouter spines.

Fig. 2. Lepeophtheirus semicossyphi Yamaguti. A-D, female; A, 1st leg; B, 2nd leg; $\mathrm{C}$, 3rd leg; D, 4th leg; E-H, male; E, 2nd antenna and 1st and 2nd maxillae in situ; $\mathrm{F}$, another view of 2nd antenna; G, 2nd maxilliped; $\mathrm{H}$, caudo-lateral angle of genital segment and a part of abdomen, showing 5th and 6th legs and caudal ramus. $\mathrm{A}-\mathrm{D}, \mathrm{G} \times 82, \mathrm{E}, \mathrm{F} \times 102, \mathrm{H} \times 120$. 


\section{IITERATURE}

Yamaguti, S., 1939. Parasitic copepods from fishes of Japan. Pt. 5, Caligoida III. Vol. Jubil. Prof. S. Yoshida 2 : 443-487, PI. XIV-XXXIII.

YAmaguti, S. and T. Yamasu, 1959. Parasitic copepods from fishes of Japan with descriptions of 26 new species and remarks on two known species. Biol. J. Okayama Univ. 5: 89-165. 